${ }^{1}$ Department of Conservative Dentistry and Prosthodontics, Al-Quds University, Palestine.

${ }^{2}$ Department of Conservative Dentistry and Prosthodontics, Arab American University, Jenin, Palestine.
Corresponding author: Dr. Naji Ziad Arandi Assistant Professor (Operative Dentistry)

Department of Conservative Dentistry and Prosthodontics Faculty of Dentistry, Arab American University, Jenin - Palestine P.O Box 240 Jenin, 13 Zababdeh. Telephone: 00972598126111

Editor: Dr Altair A. Del Bel Cury

Received: November 21, 2020 Accepted: March 9, 2021

\section{Restorative treatment decisions regarding approximal and occlusal carious lesions among general dental practitioners in Palestine}

\author{
Tarek Rabi ${ }^{\mathbb{D}}$, Naji Ziad Arandi (1)
}

Aim: To investigate restorative decisions made by dentists and to examine what demographic characteristics are associated with the decisions for managing approximal and occlusal lesions. Methods: A questionnaire was randomly sent to 900 Palestinian dentists. It noted the demographic details of the dentists and the years of experience. The questionnaire evaluated the respondents for their treatment decisions regarding approximal and occlusal carious lesions. The data was analyzed using the IBM SPSS statistics for windows. The associations between gender and years of experience of the respondents and their restorative decisions were assessed. Results: The response rate was 58.2\%. For occlusal carious lesions, 93.9\% of the respondents would postpone operative treatment until the lesion was in dentine (grade 3 to 5). For approximal lesions, intervention was deemed appropriate by $92.6 \%$ of the respondents when there was radiographic evidence of a carious lesion reaching the DEJ or deeper. Around 53\% preferred to prepare approximal lesions according to the traditional principles of cavity preparation. For both approximal and occlusal lesions, the participants opted for resin composites. Statistically, there was a significant association between the restorative decisions with the years since graduation and gender. Conclusion: The study showed variations between the treatment decisions of Palestinian dentists. The subjects chose conservative treatment plans but still adhered to traditional learned practices especially when cavity preparation for approximal lesions was concerned. The years since graduation and gender played a significant role in the choice of treatment opted for. Resin composites seemed to be a popular choice for treatment.

Keywords: Dental caries. Dental cavity preparation. Practice patterns, dentists'. Population characteristics. Composite resins. 


\section{Introduction}

Dentists all over the world face challenges with cases that are at various stages of caries progression for which they have to decide the proper management strategy. The expansion of knowledge and understanding of the various stages of caries progression, along with developments in dental materials have encouraged a fundamental change in the management of dental caries. There is considerable evidence that discourages operative management of carious lesions confined to enamel and limits it to the management of cavitated lesions ${ }^{1,2}$. Conversely, this evidence supports the management of non-cavitated early lesions by the provision of non-invasive and micro-invasive treatment strategies ${ }^{1,3,4}$.

Non-invasive strategies aim to modify the micro environment, shifting the dynamic process toward remineralisation. They do not remove dental hard tissue and involve, for example, topical fluorides and other chemical agents for controlling mineral balance, biofilm control measures and dietary control ${ }^{5}$. Micro-invasive strategies predominantly act by sealing the lesion, depriving the bacteria within of fermentable carbohydrates required for acid production. They remove the dental hard tissue surface at the micron level, usually during an etching step, such as used in sealing or resin-infiltration techniques ${ }^{2}$. Minimally-invasive operative strategies are recommended only to those lesions presenting with cavitation. Cavitation indicates the irreversible clinical endpoint of continued mineral loss and requires a surgical approach to restore form, function and plaque control. It involves removing a limited amount of gross dental hard tissue, through the use of hand excavators, rotary instruments or other devices. In most cases, this process is associated with the subsequent placement of restorations ${ }^{6,7}$.

Selecting the management strategy lies completely in the practitioners' hands. The decisions that they undertake will eventually affect the treatment costs and the tooth's restorative cycle. The thresholds for restorative treatment among dentists in the clinical settings have been studied in many countries and a wide variation in treatment modalities between and within study populations have been shown. Educational background and years of experience of the dental clinical practitioner seem to govern treatment decisions all over the world ${ }^{8-15}$. However, there have not been any studies of this nature conducted in Palestine. Therefore, this study aimed to examine restorative treatment decisions made by dental practitioners in Palestine and to investigate what demographic characteristics are associated with restorative treatment decisions made by the respondents in their management of proximal and occlusal lesions.

\section{Materials and methods}

The present study was a cross-sectional survey which was sent to 900 randomly selected general dentists from a list of those who were registered as members of the Palestinian Dental Association before December 2019. The sample size was calculated using an online sample size calculator (Raosoft.com) using a population of 4000 , marginal error of $3 \%$, a response distribution of $50 \%$ at a confidence interval of $95 \%$. This yielded a proposed sample size $n=843$, thus a 900 sample size was used for convenience. The questionnaire was presented online (Google forms) and its link was sent to the practitioners. The study started on December 12, 2019 and was completed in February 2020. A reminder 
was sent 3 and 6 weeks after the launch. The questionnaire included a brief introduction on the background, objectives, and voluntary nature of the study. Declarations of confidentiality and anonymity, instructions for filling in the questionnaire, and statement of consent were included as well. Accepting to proceed with survey was considered as an agreement to the statement of consent. Ethical approval for the study was obtained from the Research and Ethics Committee at Al-Quds University (9/REC/18). The questionnaire was adopted with modification from two previously published questionnaires ${ }^{16,17}$. Before the formal survey, a pilot study was conducted among 20 participants, who were not included in the final survey. After evaluating the responses, the questionnaire was revised and considered appropriate and then used as the final version in this survey. Through the questionnaire, socio-demographic details of the dentists were obtained and their years of experience were recorded too. In the questionnaire, the subjects were presented with an illustration of radiographic stages (1 to 6) of approximal carious lesions as shown in Figure 1. The proximal staging used was defined by radiolucency depth. They were asked at which stage they think an immediate restorative (operative) treatment is required. The dentists were also asked which type of preparation they would prefer for the smallest of the lesions they decided to need immediate restorative treatment assuming that the lesion is present distally on the upper second premolar. Three choices were given, namely traditional class II preparation, tunnel preparation, or saucer-shaped preparation. Then the respondents were asked which restorative material they would choose for the smallest approximal lesion they would restore. The options were amalgam, composite, packable glass ionomer cement (GIC), a combination of composite and resin-modified glass ionomer cement (sandwich technique).
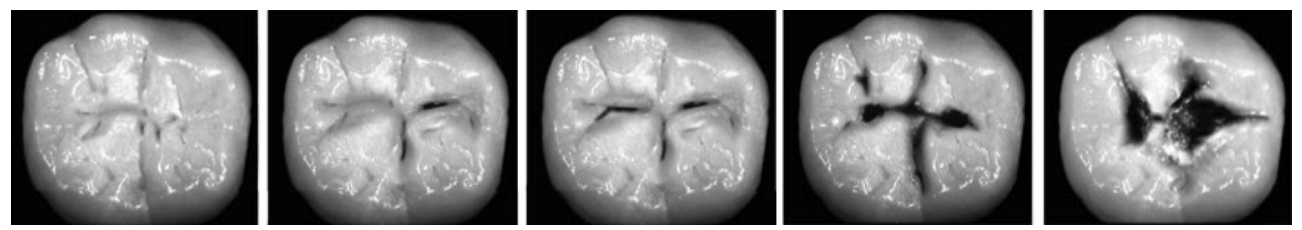

Figure 1. Shows photographs of progressive occlusal carious lesions. Grade 1 - white or brown discoloration in enamel, no clinical cavitation, no radiographic evidence of caries; Grade 2 - small cavity formation, or discoloration of the fissure with a surrounding opaque or grey zone of enamel and/or radiolucency in enamel; Grade 3 - moderately sized cavity and/or radiolucency in the outer $1 / 3$ of the dentin; Grade 4 - large cavity and/or radiolucency in the middle 1/3 of the dentin; Grade 5 - extensive cavity and/ or radiolucency in the inner $1 / 3$ of the dentin on the bitewing radiograph ${ }^{16}$

Photographs illustrating the clinical presentation of occlusal carious lesions in a lower second molar (grade 1-5) with radiographic descriptions were also presented to the participants as shown in Figure 2. The dental practitioners were asked to verify the "grade" at which immediate restorative intervention was needed for a patient who was 20 years old, used fluoridated toothpaste, had good oral hygiene, low caries activity, and visited a dentist once a year. Subsequently, the questionnaire asked the participants what restorative material they would choose to treat such teeth if the need for invasive clinical restorative treatment arises. The options were amalgam, composite, packable glass ionomer cement (GIC), a combination of composite and resin-modified glass ionomer cement (sandwich technique). 


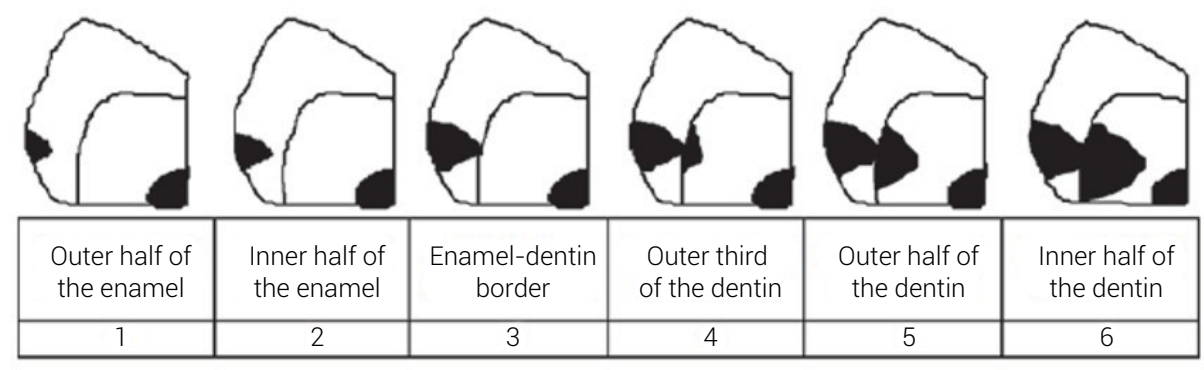

Figure 2. an illustration of the radiographic stages of approximal carious lesions ${ }^{17}$.

\section{Statistical Analysis}

The data was collected and analysed using the IBM SPSS statistics for windows. Version 25.0 (IBM Corp., Armonk, NY, USA). The statistical associations between the demographic characteristics of the dentists and their restorative decisions for approximal and occlusal lesions were assessed using Pearson's $\chi^{2}$ test. $p$-value was considered significant when less than 0.05. Fisher's exact test was used to assess statistical associations wherever Pearson's $\chi^{2}$ test is not appropriate.

\section{Results}

The response rate was 58.2\%. A total of 524 dental practitioners completed the questionnaire, 451 (86.1\%) were females and 73 (13.9\%) were males. For the years since the graduation section of the questionnaire, 166 participants displayed $0-5$ years, 190 ticked 6-10 years and 168 reported more than 10 years since graduation.

\section{Occlusal Carious Lesions with Radiographic Description}

Of the 524 participants, relatively few respondents $(n=32 ; 6.1 \%)$ chose to operatively intervene when the carious lesion is in enamel (grade II). Whereas 83 (15.8\%) chose to intervene with restorative treatment until the lesion in the outer $1 / 3$ of the dentin (grade III). The majority of the participants ( $n=409 ; 78.1 \%$ ) chose not to intervene until the lesion was in the inner third of the dentin on the radiograph (grade IV). None of the respondents would wait until the carious lesion reaches the inner third of dentine (grade V). Composite was said to be used as the restorative material of choice among 264 (50.4\%) of the participants. Preference for other restorative materials were amalgam $29.8 \%$, GIC $11.5 \%$ and $8.4 \%$ would use a combination of composite and RMGI (sandwich technique).

There was significant association $(P<0.05)$ between the gender and the restorative threshold and material of choice for restoring an occlusal lesion. There was significant association $(\mathrm{P}<0.05)$ between the years of experience and the restorative threshold and material of choice for a restoring a proximal lesion. 


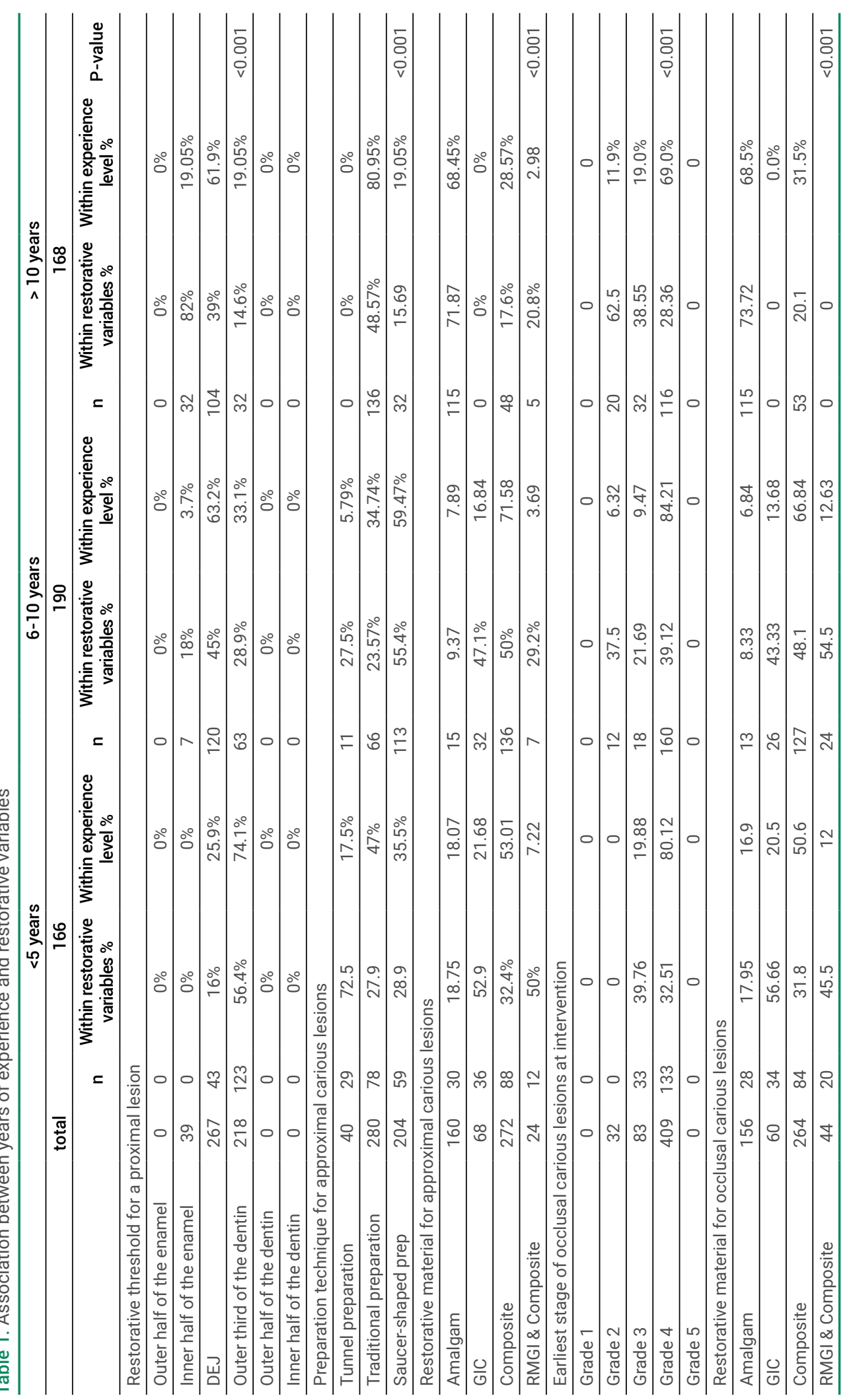




\section{Approximal Carious Lesions}

Around half ( $n=267 ; 50.9 \%$ ) of the respondents would wait until caries reach the DEJ, while 218 respondents (41.6\%) would wait until the carious lesion reaches the outer third of dentine, and 39 (7.4\%) said they would restore a carious lesion confined to the inner half of the enamel. None would operatively restore an approximate lesion limited to the outer half of the enamel nor to the inner two thirds of dentine. The preferred preparation type for 280 (53.4\%) of the participants was traditional class II, followed by the saucer-shaped preparation ( $n=204 ; 38.9 \%)$ and the least preferred cavity design the tunnel preparation $(n=40 ; 7.6 \%)$. Composite was the most preferred restorative material of 272 (51.9) of the respondents, followed by amalgam $(n=160 ; 30.5 \%)$, and $\mathrm{GIC}(n=68 ; 13 \%)$. Only $24(4.6 \%)$ chose to restore carious lesions by using the sandwich technique (RMGI and composite). There was significant association $(P<0.05)$ between the gender and the restorative threshold, preparation technique, and material of choice for restoring a proximal lesion (Table 1). The statistical analysis also showed that there was significant association $(P<0.05)$ between years of experience and the restorative threshold, preparation technique, and material of choice for a restoring a proximal lesion (Table 2).

Table 2. Association between years of experience and restorative variables

\begin{tabular}{|c|c|c|c|c|c|c|c|c|}
\hline & & & Males & & & Females & & \\
\hline & \multirow[t]{2}{*}{ total } & & $\mathrm{n}=73$ & & & $n=451$ & & \\
\hline & & $\mathrm{n}$ & $\begin{array}{c}\text { Within } \\
\text { restorative } \\
\text { variables \% }\end{array}$ & $\begin{array}{c}\text { Within } \\
\text { gender } \\
\%\end{array}$ & $\mathrm{n}$ & $\begin{array}{c}\text { Within } \\
\text { restorative } \\
\text { variables \% }\end{array}$ & $\begin{array}{c}\text { Within } \\
\text { gender } \\
\%\end{array}$ & $p$-value \\
\hline \multicolumn{9}{|c|}{ Restorative threshold for approximal lesions } \\
\hline Outer half of the enamel & 0 & 0 & 0 & 0 & 0 & 0 & 0 & \\
\hline Inner half of the enamel & 39 & 28 & 71.8 & 38.36 & 11 & 28.2 & 2.44 & \\
\hline DEJ & 267 & 31 & 11.6 & 42.46 & 236 & 88.4 & 52.33 & \\
\hline Outer third of the dentin & 218 & 14 & 6.4 & 19.18 & 204 & 93.6 & 45.23 & $<0.001$ \\
\hline Outer half of the dentin & 0 & 0 & 0 & 0 & 0 & 0 & 0 & \\
\hline Inner half of the dentin & 0 & 0 & 0 & 0 & 0 & 0 & 0 & \\
\hline \multicolumn{9}{|c|}{ Preparation technique for approximal carious lesions } \\
\hline Tunnel preparation & 40 & 12 & 30 & 16.44 & 28 & 70 & 6.2 & \\
\hline Traditional preparation & 280 & 50 & 17.86 & 68.5 & 230 & 82.14 & 51 & \\
\hline Saucer-shaped preparation & 204 & 11 & 5.4 & 15.06 & 193 & 94.6 & 42.8 & $<0.001$ \\
\hline \multicolumn{9}{|c|}{ Restorative material for approximal carious lesions } \\
\hline Amalgam & 160 & 11 & 6.89 & 15.06 & 149 & 93.11 & 33.04 & \\
\hline GIC & 68 & 13 & 19.12 & 17.8 & 55 & 80.88 & 12.2 & \\
\hline Composite & 272 & 37 & 13.6 & 50.7 & 235 & 86.4 & 52.1 & \\
\hline RMGI \& Composite & 24 & 12 & 50 & 16.44 & 12 & 50 & 2.66 & $<0.001$ \\
\hline \multicolumn{9}{|c|}{ Earliest stage of occlusal carious lesions at intervention } \\
\hline Grade 1 & 0 & 0 & 0 & 0 & 0 & 0 & 0 & \\
\hline
\end{tabular}


Continuation

\begin{tabular}{lcccccccc}
\hline Grade 2 & 32 & 16 & 50 & 21.92 & 16 & 50 & 3.56 & \\
\hline Grade 3 & 83 & 16 & 19.28 & 21.92 & 67 & 80.72 & 14.85 & $<0.001$ \\
\hline Grade 4 & 409 & 41 & 10.02 & 56.16 & 368 & 89.92 & 81.6 & 0 \\
\hline Grade 5 & 0 & 0 & 0 & 0 & 0 & 0 & & \\
\hline Restorative material for occlusal carious lesions & & & & & & \\
\hline Amalgam & 156 & 43 & 27.56 & 58.9 & 113 & 72.4 & 25.05 & \\
\hline GIC & 60 & 0 & 0 & $0 \%$ & 60 & 100 & 13.3 & \\
\hline Composite & 264 & 23 & 8.71 & 31.5 & 241 & 91.29 & 53.44 & \\
\hline RMGI \& Composite & 44 & 7 & 15.9 & 9.59 & 37 & 84.1 & 8.2 & $<0.001$ \\
\hline
\end{tabular}

\section{Discussion}

Questionnaire surveys help to understand the current status and decision-making process to facilitate translation of research evidence into clinical practice and reduce overtreatment. Questionnaire surveys investigating the restorative treatment threshold and caries management strategies (from diagnosis to treatment) among general practitioners have been used in Norway ${ }^{8}$, USA $^{9}$, UK $^{11}$, France ${ }^{10}$, Croatia ${ }^{12}$, Kuwait ${ }^{13}$, $\operatorname{Iran}^{14}, \mathrm{UAE}^{15}$. This study aimed to evaluate the restorative threshold, restorative treatment, and restoration materials that the general dental practitioners in Palestine use for approximal and occlusal carious lesions. To the best of our knowledge, this is the first study exploring the restorative thresholds of any group of Palestinian dentists regarding occlusal and proximal carious lesions. The majority of the respondents were females, which reflect the actual enrolment of females in dental schools. The present study reported significant difference between the gender and the restorative threshold, type of preparation and choice of restorative material used. Female dentists took a more conservative approach to restoration on the case scenario that involved approximal and occlusal lesions. Our findings are similar to those of previous studies ${ }^{13,18-20}$ where gender differences in the management of dental caries and restorative procedures were reported to be significant.

Studies from different countries have shown variations among dental practitioners in terms of restorative treatment thresholds. Chana et al. ${ }^{11}$ reported that $84.8 \%$ $(n=217)$ of the dentist who responded to a survey investigating the restorative treatment decisions in London preferred a conservative approach by only opting to operatively treat dentine lesions. In Norway, out of 2375 respondents, only $12.3 \%$ would restore posterior occlusal enamel lesions (grades 1-2) compared with $87.7 \%$ who would tend to defer operative treatment until the lesion had manifested in the dentin (grade 3 to 5$)^{8}$. Around $95.7 \%$ of the 185 dentists who responded to a similar survey in Kuwait opted to initiate operative treatment only when the occlusal lesions approached the dentine (grade 3 to 5 ) $^{13}$. Around $41 \%$ out of 1842 respondents to a survey in USA suggested an immediate restoration for an early stage of caries progression (grade 1 and 2 ), while 59.3\% would restore an occlusal lesion that involved the DEJ or deeper (grade 3 to 5$)^{9}$. The majority (60.7\% out of 770 ) of the respondents to a survey in France would wait until the lesion was in dentine (grade 3 to 
5) while $39.3 \%$ would restore a lesion confined to enamel (grades 1 and 2$)^{10}$. The results of the present study are consistent with previous studies ${ }^{8-11,13}$, the majority of the respondents (93.9\%) would postpone operative treatment until the lesion was in dentine (grade 3 to 5) and fewer (6.1\%) would start operative treatment earlier for a lesion confined to enamel (grade 1 and 2). However, Gordan et al. ${ }^{19}$ stated that not all of the thresholds are appropriate; some may be too conservative and some too aggressive, but no one has yet identified the "right" threshold. They added, that at present, the only thresholds that definitely can be identified as not appropriate are those that call for surgical treatment when caries is confined to enamel, owing to enamel lesions' potential for arrest or reversal.

In analysing the treatment threshold of approximal carious lesions, the participants in this study showed that intervention was deemed appropriate by the majority (92.6\%) of the respondents when there was radiographic evidence of a carious lesion reaching the DEJ or deeper. In contrast to this conservative behaviour, almost $7.4 \%$ of the respondents would recommend restorative intervention at much earlier stages with lesions confined to the enamel. This attitude (intervening when lesions are confined to enamel) is inconsistent with the literature and potential remineralisation and reversal of these lesions ${ }^{21}$. Similar to the results of the present study, the majority of dentists in Kuwait ${ }^{13}, U_{K}{ }^{11}$, Iran ${ }^{14}$, Croatia ${ }^{12}$, and USA ${ }^{9}$ opted to interfere operatively only when the approximal carious lesion had reached the dentine.

Although there have been great advances in the field of restorative dentistry, quite many participants (53.4\%) opted for traditional class II preparations. Similarly, most respondents in Kuwait ${ }^{13}, \mathrm{UK}^{11}$, and USA ${ }^{9}$ chose the traditional class II approach. The GV Black preparation requires removal of a large amount of healthy tooth structure to gain access to very small areas of proximal caries so that a restoration can be placed. This traditional preparation is unnecessarily invasive if restoring small approximal lesions with resin composite. An alternative tooth substance preserving cavity design is either the tunnel preparation or the minimal slot preparation. The tunnel preparation which leaves the marginal ridge unaffected during preparation is quite popular among dentists in Croatia ${ }^{12}$. This preparation technique was the least preferred by the respondents to the present survey. Only $7.6 \%$ of the respondents opted for this preparation technique. This might be due to the difficulty of completely removing the caries and the subsequent frequent collapse of the marginal ridge. In the slot preparation, access is achieved through the marginal ridge, but preserving this structure where ever possible. Slot preparations aim to keep removal of healthy tooth structure to a minimum and therefore have been reported to perform significantly better than tunnel restorations ${ }^{22}$. A study among dental practitioners in the College of Dentistry at Ajman University - UAE reported that the most preferred cavity design for aproximal lesions was the simple box preparation (72.8\%), followed by tunnel preparation (20.6\%) and the least preferred was the conventional class II preparation (6.7\%) $)^{15}$.

The most preferred material to restore both occlusal and proximal cavities by the respondents was composite resins. The respondents' preferences correspond to the trend towards the teaching of posterior composite restorations over amalgam restorations in dental schools provided that the majority of participants being recent graduates. The results of the present study follow along with those of similar studies ${ }^{10-13,15}$. 
The findings of this study support other researches where the treatment decisions regarding occlusal and approximal carious lesions and the demographic factors of the dentists were interlinked. The significant differences found could be due to the fact that there are various methods of teaching restorative dentistry during the learning phase of dentists. Therefore, the diagnosis and treatment plan differs from one clinical practitioner to the other.

The limitations of this study were that the data collected through the questionnaire was heavily influenced by self-reported clinical practices of the dentists and the participants were presented with hypothetical scenarios. Therefore, the answers of the participants might not have accurately depicted their clinical and practical treatment plans. In addition, the present study does not highlight treatment modalities like selective removal of caries in deep dentin lesion to prevent pulp exposure and clinical judgement of the practitioners on the same. This can be added in the present questionnaire to explore more scope in attitude of the dentists in pulp preservation. Another limitation of this is that the questionnaire is based on a given scenario and therefore the results of this study only reflect the treatment decisions of this scenario. It has been reported that the restorative decisions of dentists will change depending on the caries risk of the patient ${ }^{23,24}$. Nevertheless, even if questionnaire surveys are not able to assess the dentists' specific clinical decisions, they can still provide a good indication of their treatment modalities and knowledge. Also, it could help in the development of guidelines for dentists' education and promoting better practices. Further studies should investigate the provision of non-invasive and micro-invasive treatment strategies in the management of early lesions.

In conclusion, this study was successful in portraying that for approximal and occlusal lesions, Palestinian dentists delayed invasive restorative intervention until the carious lesions progressed to the dentin. The subjects were conservative but still adhered to traditional learned practices especially when cavity preparation for approximal lesions were concerned. The years since graduation and gender played a significant role in the choice of treatment opted for in our study. Also, resin materials seemed to be a popular choice for treatment and this shows the changing trends in dental education and research.

\section{Conflict of interests}

All authors declare that there is no conflict of interests.

\section{Ethics approval}

This study approved by the Research and Ethics Committee at Al-Quds University (9/ $\mathrm{REC} / 18)$. There is no conflict with ethical considerations.

\section{Funding}

Self-financed.

\section{Acknowledgements}

None 


\section{References}

1. Dorri M, Sm D, Walsh T, Schwendicke F. Micro-invasive interventions for managing proximal dental decay in primary and permanent teeth. Cochrane Database Syst Rev. 2015 Nov 5;(11):CD010431. doi: 10.1002/14651858.CD010431.pub2.

2. Splieth $\mathrm{CH}$, Kanzow P, Wiegand A, Schmoeckel J, Jablonski-Momeni A. How to intervene in the caries process: proximal caries in adolescents and adults-a systematic review and meta-analysis. Clin Oral Investig. 2020 May;24(5):1623-36. doi: 10.1007/s00784-020-03201-y.

3. Fontana M, Platt JA, Eckert GJ, González-Cabezas C, Yoder K, Zero DT, et al. Monitoring of Sound and Carious Surfaces under Sealants over 44 Months. J Dent Res. 2014 Nov;93(11):1070-5. doi: 10.1177/0022034514551753.

4. Liang Y, Deng Z, Dai X, Tian J, Zhao W. Micro-invasive interventions for managing non-cavitated proximal caries of different depths : a systematic review and meta-analysis. Clin Oral Investig. 2018 Nov;22(8):2675-84. doi: 10.1007/s00784-018-2605-9.

5. Walsh LJ, Brostek AM. Minimum intervention dentistry principles and objectives. Aust Dent J. 2013 Jun;58 Suppl 1:3-16. doi: 10.1111/adj.12045.

6. Laske M, Opdam NJM, Bronkhorst EM, Braspenning JCC, Van Der Sanden WJM, Huysmans MCDNJM, et al. Minimally invasive intervention for primary caries lesions: are dentists implementing this concept? Caries Res. 2019;53(2):204-16. doi: 10.1159/000490626.

7. Dallı M, Çolak H, Mustafa Hamidi M. Minimal intervention concept: a new paradigm for operative dentistry. J Investig Clin Dent. 2012 Aug;3(3):167-75. doi: 10.1111/j.2041-1626.2012.00117.x.

8. Kopperud SE, Tveit B, Opdam NJM. Occlusal Caries Management : Preferences among Dentists in Norway. Caries Res. 2016;50(1):40-7. doi: 10.1159/000442796.

9. Rechmann P, Doméjean S, Rechmann BMT, Kinsel R, Featherstone JDB. Approximal and occlusal carious lesions Restorative treatment decisions by California dentists. J Am Dent Assoc. 2016 May;147(5):328-38. doi: 10.1016/j.adaj.2015.10.006.

10. Doméjean S, Léger S, Maltrait M, Espelid I, Tveit AB, Tubert-Jeannin S. Changes in occlusal caries lesion management in France from 2002 to 2012: a persistent gap between evidence and clinical practice. Caries Res. 2015;49(4):408-16. doi: 10.1159/000381355.

11. Chana P, Orlans MC, O'Toole S, Domejean S, Movahedi S, Banerjee A. Restorative intervention thresholds and treatment decisions of general dental practitioners in London. Br Dent J. 2019 Oct;227(8):727-32. doi: 10.1038/s41415-019-0849-72.

12. Baraba A, Anić I, Doméjean-Orliaguet S, Espelid I, Tveit AB, Miletić I. Survey of Croatian dentists' restorative treatment decisions on approximal caries lesions. Croat Med J. 2010 Dec;51(6):509-14. doi: $10.3325 / \mathrm{cmj} .2010 .51 .509$.

13. Khalaf ME, Alomari QD, Ngo H, Doméjean S. Restorative treatment thresholds: Factors influencing the treatment thresholds and modalities of general dentists in Kuwait. Med Princ Pract. 2014;23(4):357-62. doi: 10.1159/000363184.

14. Ghasemi H, Murtomaa H, Torabzadeh H, Vehkalahti M. Restorative treatment threshold reported by Iranian dentists. Community Dent Health. 2008 Sep;25(3):185-90.

15. Suliman A, Abdo A, Elmasmari H. Restorative treatment decisions on approximal caries among practicing dentists in the college of dentistry clinics, Ajman University, United Arab Emirates. Open Dent J. 2020;14(1):97-102. doi: 10.2174/1874210602014010097.

16. Espelid I, Tveit AB, Mejàre I, Sundberg H, Hallonsten AL. Restorative treatment decisions on occlusal caries in Scandinavia. Acta Odontol Scand. 2001 Feb;59(1):21-7. doi: 10.1080/000163501300035724. 
17. Tveit AB, Espelid I, Skodje F. Restorative treatment decisions on approximal caries in Norway. Int Dent J. 1999 Jun;49(3):165-72. doi: 10.1002/j.1875-595x.1999.tb00902.x.

18. Riley JL, Gordan V V., Rouisse KM, McClelland J, Gilbert GH. Differences in male and female dentists' practice patterns regarding diagnosis and treatment of dental caries Findings from the Dental Practice-Based Research Network. J Am Dent Assoc. 2011 Apr;142(4):429-40.

19. Gordan V V., Bader JD, Garvan CW, Richman JS, Qvist V, Fellows JL, et al. Restorative treatment thresholds for occlusal primary caries among dentists in the Dental Practice-Based Research Network. J Am Dent Assoc. 2010 Feb;141(2):171-84. doi: 10.14219/jada.archive.2010.0136.

20. Doméjean-Orliaguet S, Léger S, Auclair C, Gerbaud L, Tubert-Jeannin S. Caries management decision: Influence of dentist and patient factors in the provision of dental services. J Dent. 2009 Nov;37(11):827-34. doi: 10.1016/j.jdent.2009.06.012.

21. Ten Cate JM. Remineralization of deep enamel dentine caries lesions. Aust Dent J. 2008 Sep;53(3):281-5. doi: 10.1111/j.1834-7819.2008.00063.x.

22. Hörsted-Bindslev P, Heyde-Petersen B, Simonsen P, Baelum V. Tunnel or saucer-shaped restorations: a survival analysis. Clin Oral Investig. 2005 Dec;9(4):233-8. doi: 10.1007/s00784-005-0011-6.

23. Heaven TJ, Gordan V V, Litaker MS, Fellows JL. Agreement among dentists ' restorative treatment planning thresholds for primary occlusal caries, primary proximal caries, and existing restorations: Findings from The National Dental Practice-Based Research Network. J Dent. 2013 Aug;41(8):71825. doi: 10.1016/j.jdent.2013.05.014.

24. Kakudate N, Sumida F, Matsumoto Y, Manabe K, Yokoyama Y, Gilbert GH, et al. Restorative Treatment Thresholds for Proximal Caries in Dental PBRN. J Dent Res. 2012 Dec;91(12):1202-8. doi: 10.1177/0022034512464778. 